Preface

\title{
From the Managing Interim Co-Editor
}

\section{Continuing the conversation: First words on the new format}

\author{
Heather McCullough \\ Director: Language Resource Center The University of North Carolina at Charlotte \\ Managing Interim Co-Editor IALLT
}

\section{Introduction to IALLT Journal Online}

This issue formally marks the transformation of the IALLT Journal from its previous print format to its new fully online electronic format. The change in formats strikes me as both a significant event and yet also quite a normal progression for the journal. The reverence for print in our academic culture in the humanities and literature continues to remain high and so it is with a bit of nostalgia perhaps that this first online issue appears. On the other hand, this new format will enable discussions of technology-enhanced language instruction potentially to reach a much wider audience, and in this way the electronic format will strengthen the community of language and technology enthusiasts while also extending the reach and impact of the ideas expressed in the journal.

Although this first issue was not organized around a single topic, a common theme emerges from the three articles that seems fitting for this first online issue. Quite simply, all three examine how the increased facility for communicating and collaborating with new tools affords new opportunities for students and teachers alike. Students have more possibilities for using and developing their language skills and for experiencing and interacting with peers in other cultures via online tools. Instructors have increased opportunities for developing learning activities and for collaborating with each other. Indeed, models of service and support provided to students and teachers may have to shift to accommodate these changes. It takes effort and thought by the individual student, teacher, and by groups, such as learning centers and national organizations, to determine how new technologies can be adopted to help meet particular goals. However, as each of the articles affirms, the new communication and learning tools available offer interesting ways of enriching learning about foreign languages and cultures.

The process of creating the new online journal required, as one would expect, collaborative work from numerous people working on different pieces of this complex puzzle of a project. The decision to move to an online format was carefully considered and given support by the IALLT leadership. Both current IALLT President Barbara Sawhill and outgoing president Claire Bartlett provided guidance to the entire team through the process. They and the IALLT Board should be commended for gathering up the collective energy of the people involved and for helping to define the vision of the project. Martin 
Holmes of the University of Victoria Humanities Computing and Media Centre provided invaluable programming expertise and built a custom XML template for the IALLT Journal. He also did all of the encoding of the text in this issue and had a keen eye for grammar and style issues as well. My colleague and co-editor Doug Canfield contributed significantly in all areas of the online journal's developing and is overseeing the journal's inclusion into the major library databases to increase further its potential reach. Finally, our most important collaborators, our authors, were incredibly accommodating waiting for the appearance of this journal and we thank them for their work and patience. Each person involved in this first issue contributed a vital element without which the online journal might not have been created. In this way, the project itself epitomized the best of collaborative learning where we all worked together to develop something new and significant.

As we move forward with additional online issues, it is difficult to predict what kinds of language learning technologies will be described in the journal "pages" of the future. Although we might not be able precisely to image the technologies that will be used in 10 -15 years, the goals of language study to understand the world around us, to understand cultures and practices that are different from ours, to have new tools for engaging with the world, and to understand our own cultures and practices will not change. This first online issue is a significant step in the journal's history, but it carries forward unchanged the mission of the print IALLT Journal to facilitate discussion and dialogue among language educators, administrators, and staff members at language resource centers and labs. As a final message, I would like to encourage readers of this issue to consider writing and submitting an article for the journal and joining the active dialogue we hope to encourage among language learning and technology professionals. 